\title{
CAVIDADES NATURAIS SUBTERRÂNEAS: AS HIPÓTESES DE INTERVENÇÃO E MEDIDAS COMPENSATÓRIAS INCIDENTES NO BRASIL
}

\author{
NATURAL SUBTERRANEAN CAVES: THE HYPOTHESIS OF \\ INTER VENTION AND COMPENSATORY MEASURES IN \\ BRAZIL
}

\author{
${ }^{1}$ Jhenne Celly Pimentel de Brito \\ ${ }^{2}$ Ricardo Carneiro
}

\section{RESUMO}

Considerando a importância da preservação do meio ambiente e do patrimônio cultural brasileiro, neles incluído o patrimônio espeleológico, e o existente conflito resultante do desenvolvimento de atividades econômicas em áreas de ocorrência de cavernas, o presente artigo prevê a análise das hipóteses de intervenção em cavidades naturais subterrâneas localizadas no Brasil e as medidas compensatórias incidentes, tendo em vista o previsto no Decreto $\mathrm{n}^{\circ}$ 99.556, de 01.10.1990, alterado pelo Decreto $\mathrm{n}^{\circ} 6.640$, de 07.11.2008, e na Lei $\mathrm{n}^{\circ}$ 6.938, de 31.08.1981, em paralelo com a viabilidade enfrentada pelos empreendimentos na execução da medida compensatória, no que concerne às cavidades de testemunho.

Palavras-chave: Cavidades naturais subterrâneas, Cavernas, Compensação

\begin{abstract}
Considering the importance of the preservation of the environment and the cultural patrimony of Brazil, including the speleological patrimony, and the existing conflict resulted by the development of economic activities in cave zones, the present article displays the analyses of the hypothesis of intervention in natural subterranean caves located in Brazil and the occurring compensatory measures, regarding the stated in Decree 99.556, of 10.01.1990, altered by the Decree 6.640, of 11.07.2008, and in Law 6.938, of 08.31.1981, in parallel with the viability dealt by enterprises in the accomplishment of the compensatory measure, concerning the preserved caves.
\end{abstract}

Keywords: Natural subterranean cave, Caves, Compensation

\footnotetext{
${ }^{1}$ Mestranda em Direito pela Escola Superior Dom Helder Câmara -ESDHC. Belo Horizonte. Minas Gerais. Advogada na Ricardo Carneiro Advogados Associados, Belo Horizonte, Minas Gerais, (Brasil) Email: tutortreinamento@ gmail.com

${ }^{2}$ Mestre em Direito Econômico pela Faculdade de Direito da Universidade Federal do Estado de Minas Gerais -UFMG, Belo Horizonte, Minas Gerais. Advogado na Ricardo Carneiro Advogados Associados, Belo Horizonte, Minas Gerais, (Brasil).
} 


\section{INTRODUÇÃO}

As cavidades naturais subterrâneas integram o patrimônio espeleológico brasileiro por sua relevância natural e cultural, incidindo sobre elas medidas de proteção e preservação que objetivam resguardar não apenas a função ecossistêmica como a relevância histórica e arqueológica.

Ocorre que, algumas atividades, por rigidez locacional, são desenvolvidas em áreas de características geológicas semelhantes às de ocorrência das cavidades, causando conflito entre a necessária proteção do bem ambiental e o crescimento econômico dos setores industriais.

Nesse contexto, tendo por base o princípio do desenvolvimento sustentável, a legislação brasileira prevê parâmetros de relevância das cavidades, classificando-as em máxima, alta, média e baixa relevância, para que seja possível avaliar durante o licenciamento ambiental dos empreendimentos causadores de impacto ambiental, aquelas hipóteses em que as estruturas podem ser suprimidas ou não.

Desse modo, é vedado o impacto irreversível em cavidades de máxima relevância ambiental e cultural, como, por exemplo, são classificadas a Gruta da Lapinha, localizada em Lagoa Santa/MG, e a Gruta de Maquiné, em Cordisburgo/MG, pela importância paleontológica, histórica, turística, ecológica e geológica.

Para as demais classes de relevância, permite-se a intervenção, desde que atendidos os critérios definidos no Decreto $n^{\circ} 99.556$, de 01.10.1990, alterado pelo Decreto $n^{\circ}$ 6.640, de 07.11.2008, e adotadas as medidas compensatórias incidentes.

Como bem observa Bechara

[...] a compensação tem por finalidade primordial fazer com que uma atividade degradadora ou poluidora que afete negativamente o equilibrio ambiental, por agredir algum de seus elementos corpóreos ou incorpóreos, ofereça uma contribuição para afetálo positivamente, melhorando a situação de outros elementos corpóreos ou incorpóreos não afetados. (BECHARA, 2009, p. 136).

Tanto é assim que, para as intervenções em cavidades de alta relevância, torna-se necessária a preservação, em caráter permanente, de outras duas cavidades, correspondendo às chamadas cavidades testemunho.

Sob essa perspectiva, atualmente, impõe-se à atividade minerária o conflito entre as frentes de lavra e a existência de cavidades naturais, sendo imperativa a avaliação precisa do 
grau de relevância dessas cavernas para que se possa concluir acerca da viabilidade ambiental, econômica e locacional do empreendimento a ser implantado.

Apresentadas, ainda que objetivamente, a relevância e a situação de conflito existente entre a proteção do patrimônio espeleológico e as atividades mineradoras, cumpre avaliar os instrumentos jurídicos pátrios que possibilitem a intervenção nessas estruturas por meio de medida compensatória, bem como algumas problemáticas de interpretação de seus dispositivos, possibilitando, assim, a proteção de cavidades naturais subterrâneas e o desenvolvimento econômico.

Importante salientar que não há intenção de esgotar o debate sobre o tema proposto, mas, busca-se, através de uma abordagem preliminar e parcial, colaborar com as discussões acerca das hipóteses de compensação ambiental espeleológica e o desenvolvimento sustentável.

Sendo utilizado, para o alcance dos objetivos traçados, o método de abordagem qualitativo, empregando-se as técnicas de pesquisa bibliográfica, com coleta de legislação, jurisprudência e doutrina.

\section{A PROTEÇÃo do PATRIMÔNiO ESPELEOLÓgICO E AS HIPÓTESES DE INTERVENÇÃO PERMITIDAS NA LEGISLAÇÃO}

As cavidades naturais subterrâneas existentes no Brasil constituem os bens dominiais da União de que trata o artigo 20, inciso $X$, da Constituição Federal, de resto não sendo poucos os que, no plano doutrinário, passaram a também enquadrar as cavernas como integrantes do patrimônio cultural brasileiro, para os fins consignados no artigo 216 da Carta Republicana, que assim qualificou os sítios de valor histórico, paisagístico, artístico, arqueológico, paleontológico, ecológico e científico.

Em consequência, impõe-se ao poder público e à coletividade a necessidade de sua preservação e conservação objetivando possibilitar estudos, pesquisas e atividades de ordem técnico-cientifica, étnica, cultural, espeleológica, turístico, recreativo e educativo, para as presentes e futuras gerações.

O conceito de cavidade natural subterrânea é definido pelo paragrafo único do artigo $1^{\text {o }}$ do Decreto $n^{\circ} 99.556 / 1990$ do seguinte modo:

Parágrafo único. Entende-se por cavidade natural subterrânea todo e qualquer espaço subterrâneo acessível pelo ser humano, com ou sem abertura identificada, 
popularmente conhecido como caverna, gruta, lapa, toca, abismo, furna ou buraco, incluindo seu ambiente, conteúdo mineral e hídrico, a fauna e a flora ali encontrados e o corpo rochoso onde os mesmos se inserem, desde que tenham sido formados por processos naturais, independentemente de suas dimensões ou tipo de rocha encaixante.

Desse modo, haja vista a importância de tais estruturas naturais ao patrimônio ambiental e cultural brasileiro, o $\S 1^{\circ}$ do o artigo 216 da Constituição Federal estabelece que -o Poder Público, com a colaboração da comunidade, promoverá e protegerá o patrimônio cultural brasileiro, por meio de inventários, registros, vigilância, tombamento e desapropriação, e de outras formas de acautelamento e preservaçãoll.

Nesse sentido ressalta MIRANDA (2012, p. 54):

A proteção desses locais é de fundamental importância em razão de sua relevância para o meio ambiente natural e cultural. Com efeito, as cavidades naturais subterrâneas compõem ecossistemas de intensa complexidade e de grande fragilidade ambiental, com significativo endemismo faunístico, beleza cênica, multiplicidade de feições morfológicas, deposições minerais de diversos formatos (espeleotemas) e estratégicos reservatórios de água, além de comumente guardarem vestígios paleontológicos (p. ex., megafauna extinta), arqueológicos (p. ex., pinturas rupestres e sepultamentos pré-históricos) e de mudanças climáticas (paleoclima), de fundamental importância para melhor compreensão da evolução da vida sobre a Terra.

Isso porque, conforme HENKES et al (2013, p.240), -a proteção do patrimônio cultural possibilitará à sociedade manter vínculos com o passado, proporcionando o enraizamento, a manutenção da história e a memória da sociedade brasileirall.

Sob outra perspectiva, bem ressalta SILVA (2005, p.809):

Não se trata de proteger juridicamente todas as manifestações culturais, mas apenas os bens de natureza material ou imaterial que sejam „portadores de referência à identidade, à ação, à memória dos diferentes grupos formadores da sociedade brasileira.

Nesse ponto observa-se que, nem toda caverna - melhor seria dizer, a minoria delas - traz referência aos grupos constitutivos de nossa sociedade em sua atual conformação, quais sejam os portugueses, os negros africanos, os índios e os imigrantes estrangeiros de diversas origens, lugares e etnias.

Certo é que, nos dias atuais, dificilmente se encontraria cavidades com características tão peculiares em áreas de lavra, por já estarem preservadas áreas territoriais de proteção ambiental. 
Tendo em vista tais apontamentos iniciais, deve-se ter em mente que, em algumas ocasiões, para que se viabilize o desenvolvimento de uma atividade econômica, há o impacto negativo em cavidades localizadas na área de implantação do empreendimento.

Essa intervenção deve ser avaliada mediante prévio licenciamento ambiental, para que verifique a admissibilidade ou não dos impactos ambientais considerados irreversíveis às cavidades naturais, conforme os critérios técnicos e as metodologias de valoração estabelecidos pelo Ministério do Meio Ambiente - MMA, por meio da Instrução Normativa $\mathrm{n}^{\mathrm{o}} 2$, de 20.08.2009.

\subsection{A NECESSÁria PROTEÇÃo Do PATRIMÔNiO ESPELEOLÓGICO E O DESENVOLVIMENTO SUSTENTÁVEL}

Em contraponto à proteção constitucional do meio ambiente ecologicamente equilibrado, têm-se o estímulo ao crescimento econômico, sendo imperativa a compatibilização dos institutos, por meio do princípio do desenvolvimento sustentável.

Conforme entendimento da Comissão Mundial sobre o Meio Ambiente e Desenvolvimento Sustentável, -o desenvolvimento sustentável é o desenvolvimento que atende às necessidades dos presentes, sem comprometer a possibilidade das gerações futuras satisfazerem suas próprias necessidades\| 1 ( BRUNDTLAND, Gro Harlem. 1987, Chapter 2: Towards Sustainable Development, $n^{o}$,- Tradução nossa).

Em síntese, o desenvolvimento sustentável encontra respaldo na interpretação sistemática dos dispositivos constitucionais, dentre eles os artigos 225 e 170, haja vista a necessária compatibilização dos princípios norteadores da ordem econômica nacional e aqueles voltados à proteção do meio ambiente, para que se torne possível o crescimento de atividades impactantes.

Art. 170. A ordem econômica, fundada na valorização do trabalho humano e na livre iniciativa, tem por fim assegurar a todos existência digna, conforme os ditames da justiça social, observados os seguintes princípios:

$[\ldots]$

VI - defesa do meio ambiente, inclusive mediante tratamento diferenciado conforme o impacto ambiental dos produtos e serviços e de seus processos de elaboração e prestação; (Redação dada pela Emenda Constitucional nº 42, de 19.12.2003)

\footnotetext{
1 "Sustainable development is development that meets the needs of the present without compromising the ability of future generations to meet their own needs." (Brudtland Report, Our Common Future, Chapter 2: Towards Sustainable Development, $n^{\circ} 1$ )
} 
Art. 225. Todos têm direito ao meio ambiente ecologicamente equilibrado, bem de uso comum do povo e essencial à sadia qualidade de vida, impondo-se ao Poder Público e à coletividade o dever de defendê-lo e preservá- lo para as presentes e futuras gerações.

De modo complementar, a Lei $n^{\circ}$ 6.938, de 31.08.1981, a Política Nacional do Meio Ambiente - PNMA, estrutura no seu artigo $2^{\circ}$, caput, o objetivo geral da Lei, voltado para o controle da qualidade ambiental propícia à vida, assegurando o desenvolvimento socioeconômico de forma equilibrada e protegendo a dignidade da vida humana.

Art $2^{\circ}$ - A Política Nacional do Meio Ambiente tem por objetivo a preservação, melhoria e recuperação da qualidade ambiental propícia à vida, visando assegurar, no País, condições ao desenvolvimento sócio-econômico, aos interesses da segurança nacional e à proteção da dignidade da vida humana, atendidos os seguintes princípios:

Noutro ponto, o artigo $4^{\circ}$ estabelece objetivos específicos da PNMA como a associação do desenvolvimento econômico à preservação do meio ambiente, a utilização racional do bem ambiental, a imposição ao poluidor de recuperar e/ou indenizar eventuais danos causados ao meio ambiente.

Art. $4^{\circ}$ - A Política Nacional do Meio Ambiente visará:

I - à compatibilização do desenvolvimento econômico social com a preservação da qualidade do meio ambiente e do equilíbrio ecológico;

II - à definição de áreas prioritárias de ação governamental relativa à qualidade e ao equilíbrio ecológico, atendendo aos interesses da União, dos Estados, do Distrito Federal, do Territórios e dos Municípios;

III - ao estabelecimento de critérios e padrões da qualidade ambiental e de normas relativas ao uso e manejo de recursos ambientais;

IV - ao desenvolvimento de pesquisas e de tecnologia s nacionais orientadas para o uso racional de recursos ambientais;

$\mathrm{V}$ - à difusão de tecnologias de manejo do meio ambiente, à divulgação de dados e informações ambientais e à formação de uma consciência pública sobre a necessidade de preservação da qualidade ambiental e do equilibrio ecológico;

VI - à preservação e restauração dos recursos ambientais com vistas á sua utilização racional e disponibilidade permanente, concorrendo para a manutenção do equilíbrio ecológico propício à vida;

VII - à imposição, ao poluidor e ao predador, da obrigação de recuperar e/ou indenizar os danos causados, e ao usuário, de contribuição pela utilização de recursos ambientais com fins econômicos.

Deve-se ter em mente que, por mais relevante que seja a proteção que a Constituição Federal confere à cultura ou ao meio ambiente, não se deve atribuir aos deveres que disso se originam nenhum caráter absoluto, diante da possibilidade — sempre concreta —, de que 
venham eles a concorrer com outras garantias ou mesmo com bens jurídicos igualmente revestidos de estatura constitucional.

É bem este o caso das atividades exercidas no interesse nacional, tais aquelas relacionadas à pesquisa e à lavra de substâncias minerais - com regime jurídico inserido na Constituição e dependente do uso de bens de domínio da União - , quando eventualmente previstas para se implantarem em áreas de ocorrência de cavidades naturais subterrâneas reconhecidas por seu valor ecológico, paleontológico, estético ou paisagístico.

Dentro dessa dinâmica, e em decorrência mesmo do interesse nacional que lhe é intrínseco, o regime jurídico inerente à pesquisa e ao aproveitamento das substâncias minerais previstos no Decreto-Lei $\mathrm{n}^{\mathrm{o}} 227$, de 28.02.1967, impõe ao interessado que efetivamente realize as atividades minerárias a ele autorizadas/outorgadas, sendo vedado ao minerador interromper os trabalhos exploratórios ou extrativos, salvo mediante anuência do Departamento Nacional de Produção Mineral - DNPM, nos termos dos artigos 29 e 49 do Código de Mineração.

Nesse contexto, é importante observar que o desenvolvimento de grandes projetos, principalmente aqueles voltados à atividade minerária, por similaridade geológica entre as áreas de lavra e as de ocorrência de cavidades naturais, enfrentam a avaliação de possíveis impactos nessas estruturas.

Tal análise - ocorrida na fase de licenciamento ambiental e durante a elaboração de Estudos de Impacto Ambientais (EIA) e Relatório de Impacto Ambiental (RIMA)—, torna-se imprescindível à conclusão acerca da viabilidade ambiental e econômica do empreendimento a ser implantado.

Conforme destaca MILARÉ (2014, p.789):

[...] o licenciamento constitui importante instrumento de gestão do ambiente, na medida em que, por meio dele, a Administração Pública busca exercer o necessário controle sobre as atividades humanas que interferem nas condições ambientais, de forma a compatibilizar o desenvolvimento econômico com a preservação do equilíbrio ecológico. Isto é, como prática do poder de policia administrativa, não deve ser considerado um obstáculo teimoso ao desenvolvimento, como, infelizmente, muitos assim enxergam.

Na hipótese de ser encontrado intenso número de cavidades, a conclusão dos estudos ambientais pode resultar na inviabilidade do projeto por onerosidade na execução de medidas compensatórias, quando permitidas, ou da impossibilidade da implantação por inviabilidade 
ambiental, quando as cavidades encontradas guardarem características peculiares que impeçam sua supressão.

Desse modo, por mais que se considere a chamada rigidez locacional dos aproveitamentos minerários, consistente no fato de que os recursos do solo ou do subsolo somente podem ser explorados onde apresentem ocorrência geológica, a viabilidade do desenvolvimento das atividades dependerá dessas circunstâncias.

Assim, para compatibilizar o exercício de tais atividades econômicas, são permitidas algumas hipóteses de intervenção em cavidades, condicionadas à medida compensatória correlata ou em respeito ao limite de área de influência da cavidade, estabelecido pela legislação em um raio de $250 \mathrm{~m}^{2}$, de modo a possibilitar, assim, a proteção de cavidades naturais subterrâneas e o desenvolvimento econômico.

\subsection{DAS HIPÓTESES DE INTERVENÇÃO PERMITIDAS NA LEGISLAÇÃO BRASILEIRA}

É importante observar que, o Decreto $\mathrm{n}^{\circ}$ 99.556, de 01.10.1990, alterado pelo Decreto $\mathrm{n}^{\mathrm{o}}$ 6.640, de 07.11.2008, estabeleceu uma lógica de critérios de relevância divididos em máxima, alta, média ou baixa - conforme os quais, mediante prévio licenciamento ambiental, se tem como admissíveis ou não os impactos ambientais considerados irreversíveis às cavidades naturais, sendo que os critérios técnicos e as metodologias de valoração aplicáveis foram estabelecidos pelo Ministério do Meio Ambiente - MMA, por meio da Instrução Normativa $n^{\text {o }}$ 2, de 20.08.2009.

Art. $2^{\circ}$ A cavidade natural subterrânea será classificada de acordo com seu grau de relevância em máximo, alto, médio ou baixo, determinado pela análise de atributos ecológicos, biológicos, geológicos, hidrológicos, paleontológicos, cênicos, históricoculturais e socioeconômicos, avaliados sob enfoque regional e local. (Redação dada pelo Decreto $\mathrm{n}^{\circ}$ 6.640, de 2008).

Vedando qualquer sorte de intervenção sobre cavidades subterrâneas enquadradas em grau de relevância máxima, o novo diploma regulamentar estabeleceu, para os casos de empreendimentos causadores de impactos negativos sobre cavernas de importância considerada alta, a necessidade de preservação, em caráter permanente, de outras duas cavidades, correspondendo às chamadas cavidades testemunho. 
Art. $3^{\circ} \mathrm{A}$ cavidade natural subterrânea com grau de relevância máximo e sua área de influência não podem ser objeto de impactos negativos irreversíveis, sendo que sua utilização deve fazer-se somente dentro de condições que assegurem sua integridade física e a manutenção do seu equilíbrio ecológico. (Redação dada pelo Decreto $\mathrm{n}^{\mathrm{o}}$ 6.640, de 2008).

Art. $4^{\circ}$ A cavidade natural subterrânea classificada com grau de relevância alto, médio ou baixo poderá ser objeto de impactos negativos irreversíveis, mediante licenciamento ambiental. (Redação dada pelo Decreto $n^{\circ} 6.640$, de 2008).

$\S 1^{\circ}$ No caso de empreendimento que ocasione impacto negativo irreversível em cavidade natural subterrânea com grau de relevância alto, o empreendedor deverá adotar, como condição para o licenciamento ambiental, medidas e ações para assegurar a preservação, em caráter permanente, de duas cavidades naturais subterrâneas, com o mesmo grau de relevância, de mesma litologia e com atributos similares à que sofreu o impacto, que serão consideradas cavidades testemunho. (Incluído pelo Decreto n ${ }^{\circ} 6.640$, de 2008).

Por outro lado, na hipótese de cavidade natural de grau de relevância média, o empreendedor ficará obrigado a adotar medidas e financiar ações que contribuam para a conservação e o uso adequado do patrimônio espeleológico brasileiro, sendo que, para o caso de impacto adverso sobre cavidades de baixo grau de relevância, não será exigida qualquer medida conservacionista equivalente.

$\S 4^{\circ}$ No caso de empreendimento que ocasione impacto negativo irreversível em cavidade natural subterrânea com grau de relevância médio, o empreendedor deverá adotar medidas e financiar ações, nos termos definidos pelo órgão ambiental competente, que contribuam para a conservação e o uso adequado do patrimônio espeleológico brasileiro, especialmente das cavidades naturais subterrâneas com grau de relevância máximo e alto. (Incluído pelo Decreto n ${ }^{\circ}$ 6.640, de 2008).

$\S 5^{\circ}$ No caso de empreendimento que ocasione impacto negativo irreversível em cavidade natural subterrânea com grau de relevância baixo, o empreendedor não estará obrigado a adotar medidas e ações para assegurar a preservação de outras cavidades naturais subterrâneas. (Incluído pelo Decreto nº 6.640, de 2008).

Pelo que de logo se percebe, cada um dos grupos em que se divide os componentes do patrimônio espeleológico tem uma dinâmica protetiva peculiar, variando, no que tange ao uso econômico dos recursos naturais neles existentes, da vedação absoluta - no caso daquelas consideradas como de máxima relevância —, até a admissibilidade condicionada, como é a hipótese intrínseca às demais categorias.

Especificamente no tocante às cavernas de alta relevância, a exigência compensatória correspondente deve ser efetivada preferencialmente em área contínua e integrante do mesmo grupo geológico da estrutura geomorfológica a ser suprimida, apresentando, de resto, a mesma litologia, além de similaridade de atributos e relevância, embora o Decreto não esclareça o modo pelo qual deverá o responsável pelo estabelecimento fazê-lo, diante da 
possibilidade, sempre concreta, de que tais feições testemunho estejam localizadas em áreas distantes, pertencentes a terceiros, e, por isso mesmo, muitas vezes indisponíveis, de imediato, para aquisição, a qualquer título.

E inexistindo na área do empreendimento cavidades naturais similares, o artigo $4^{\circ}, \S$ $3^{\circ}$ do Decreto $n^{\circ} 99.556 / 1990$, com redação determinada pelo Decreto ${ }^{\circ}$ 6.640/2008, permite que o Instituto Chico Mendes defina outras formas de adequação compensatória, mediante critérios previstos na Instrução Normativa ICMBio $\mathrm{n}^{\mathrm{o}}$ 30, de 19.09.2012 e negociações encetadas diretamente com o responsável pelo empreendimento.

$\S 3^{\circ}$ Não havendo, na área do empreendimento, outras cavidades representativas que possam ser preservadas sob a forma de cavidades testemunho, o Instituto Chico Mendes poderá definir, de comum acordo com o empreendedor, outras formas de compensação. (Incluído pelo Decreto n ${ }^{\circ} 6.640$, de 2008).

Ademais, prevê o artigo $4^{\circ}, \S 3^{\circ}$ do Decreto $n^{\circ} 99.556 / 1990$, com texto alterado pelo Decreto $n^{\circ}$ 6.640/2008, que na hipótese de impactos irreversíveis negativos em cavidades na área do empreendimento, a compensação definida pela Lei no 9.985, de 18.07.2000, — Lei do Sistema Nacional de Unidades de Conservação da Natureza - SNUC - deverá ser destinada prioritariamente à criação e implementação de Unidades de Conservação em áreas de interesse espeleológico, sempre que possível na área do empreendimento.

$\S 4^{\circ}$ Em havendo impactos negativos irreversíveis em cavidades naturais subterrâneas pelo empreendimento, a compensação ambiental de que trata o art. 36 da Lei no 9.985 , de 18 de julho de 2000, deverá ser prioritariamente destinada à criação e implementação de unidade de conservação em área de interesse espeleológico, sempre que possível na região do empreendimento. (Incluído pelo Decreto n ${ }^{\circ} 6.640$, de 2008).

Outro ponto de interesse na sistemática do Decreto $n^{\circ}$ 99.556/1990, refere-se à área de influência das cavidades subterrâneas, já embrionariamente prevista no parágrafo único do artigo $6^{\circ}$ da antiga Portaria IBAMA $n^{\circ}$ 887, de 15.06.1990, cabendo registrar que a exata delimitação desta faixa, nos termos do artigo $4^{\circ}$, $\S 2^{\circ}$ da Resolução CONAMA n ${ }^{\circ} 347$, de 10.09.2004, depende de decisão do órgão ambiental competente, com base em estudos específicos realizados às expensas do empreendedor, à falta dos quais prevalece sempre a projeção horizontal da caverna, acrescida de um entorno de 250 (duzentos e cinquenta) metros, sob a forma de poligonal convexa. 
Em regra, e bem ao contrário do que sustentam alguns, não se trata aqui, em absoluto, de zona de exclusão absoluta nos contornos das cavidades, configurando apenas e tão somente um perímetro transitório de influência de seus atributos, nada havendo, no contexto da Resolução CONAMA n ${ }^{\circ} 347$, de 10.09.2004, que impeça o desenvolvimento de atividades produtivas em distâncias inferiores relativamente a essas ocorrências geológicas, certo que se as normas vigentes admitem até mesmo a remoção integral de algumas dessas estruturas, nenhum óbice pode haver ao uso econômico daquela faixa, prevalecendo aqui a ideia de que -in eo quod plus sit, semper inest et minus\| (naquilo que está contido o mais, sempre está contido o menos), impondo-se in casu reconhecer que se àquele a quem se consente o mais, ou seja, a supressão da própria caverna —, não se deve negar o menos, vale dizer, a utilização de suas adjacências.

Não se desconhece, entretanto, que o artigo $3^{\circ}$ do Decreto $n^{\circ} 99.556 / 1990$ proíbe que a cavidade natural subterrânea com grau de relevância máximo e também sua área de influência sejam expostas a atividades ou empreendimentos com impactos negativos considerados como irreversíveis.

Mais ainda: nos termos do $\S 2^{\circ}$ do artigo 21 da Instrução Normativa $n^{\circ} 2$, de 20.08.2009, as cavidades testemunho definidas no processo de licenciamento passam a contar com grau de relevância máximo, ficando vedado o desenvolvimento de atividades que afetem definitiva e irremediavelmente essas estruturas:

Art. 21. A preservação de 2 (duas) cavidades testemunho definidas em procedimento de licenciamento ambiental, será condicionante para o licenciamento de empreendimentos que causem impactos a outra cavidade de alta relevância.

$\S 1^{\circ}$. As cavidades testemunho preservadas deverão apresentar configurações similares de atributos que determinaram a classificação de alta relevância para a cavidade alvo de impactos irreversíveis.

$\S 2^{\circ}$. As cavidades testemunho definidas no processo de licenciamento têm grau de relevância máximo, ficando vedado o licenciamento de atividades que thes causem impactos irreversíveis.

Note-se, do exame articulado dessas disposições regulamentares, que somente no entorno das feições de relevância máxima se estende o regime proibitório previsto no Decreto $\mathrm{n}^{\circ}$ 99.556/1990, sendo que, no caso das cavidades de importância alta, que sirvam de sucedâneo compensatório para aquelas sujeitas a ações impactantes ou supressórias específicas, apenas as componentes espeleológicas em si mesmas consideradas - e não as respectivas áreas de influência -, ficam sujeitas a diretrizes de elevação do grau protetivo.

Dessa forma, na hipótese tutelar prevista no artigo 21, § $2^{\circ}$ da IN MMA n ${ }^{\circ} 2 / 2009$, inexiste qualquer obstáculo à incidência da compensação espeleológica, que pode 
perfeitamente se materializar - do ponto de vista físico - na área de influência delimitada para as cavidades que servem como testemunho daquelas outras de alta relevância, sujeitas a impactos ambientais irrecuperáveis.

Já no tocante ao entorno das cavernas de máxima relevância, costuma-se opor algumas objeções à alocação de cavidades testemunho, sempre ao argumento de que esta zona circunvizinha já se encontraria integralmente preservada pela regra insculpida no artigo $3^{\circ}$ do Decreto $\mathrm{n}^{\circ}$ 99.556/1990.

O raciocínio, no entanto, é enganoso, já que, de rigor, na área de influência de cavidade de máxima relevância são, sim, admitidas atividades de baixo impacto negativo e com caráter reversível, sendo que seu uso regular pode sempre ocorrer de forma lícita, desde que atenda a determinadas condições que assegurem sua integridade física e a manutenção de seu equilibrio ecológico.

Isso, por conseguinte, reforça a utilidade e a pertinência da compensação espeleológica nesses casos, contribuindo para o aumento do regime conservativo ao redor das grutas de grau máximo de importância, tudo em sintonia com o critério de continuidade territorial das feições a serem preservadas, nos termos do multicitado artigo $4^{\circ}$, $\S 2^{\circ}$ do Decreto $n^{\circ}$ 99.556/1990.

\section{AS DIFICULDADES ENFRENTADAS PARA EFETIVIDADE DA MEDIDA COMPENSATÓRIA NO QUE CONCERNE ÀS CAVIDADES DE TESTEMUNHO}

Posto tais apontamentos, deve-se discorrer sobre alguns entraves encontrados para a efetividade da medida compensatória subjacente à tutela do patrimônio espeleológico nacional, visto que existem terminologias utilizadas no Decreto $\mathrm{n}^{\circ}$ 99.556/1990, com redação alterada pelo Decreto $n^{\circ} 6.640 / 2008$, que carecem de delimitação conceitual.

O texto do artigo $4^{\circ}, \S 1^{\circ}$ do Decreto $\mathrm{n}^{\circ}$ 99.556/1990, incluído pelo Decreto $\mathrm{n}^{\circ}$ 6.640/2008, possibilita a supressão de cavidades de alta relevância, se compensadas, para cada uma delas, outras duas de igual relevância, mesma litologia ${ }^{2}$ e atributos similares, aqui chamadas de cavidades de testemunho.

Art. $4^{\circ}$ A cavidade natural subterrânea classificada com grau de relevância alto, médio ou baixo poderá ser objeto de impactos negativos irreversíveis, mediante licenciamento ambiental. (Redação dada pelo Decreto $n^{\circ} 6.640$, de 2008).

$\S 1^{\circ}$ No caso de empreendimento que ocasione impacto negativo irreversível em cavidade natural subterrânea com grau de relevância alto, o empreendedor deverá adotar, como condição para o licenciamento ambiental, medidas e ações para as segurar a preservação, emcaráter permanente,de 
duas cavidades naturais subterrâneas, como mesmo grau de relevância, de mes ma litologia e com atributos similares à que sofreu o impacto, que serão consideradas cavidades testemunho.

\footnotetext{
${ }^{2}$ O conceito de Litologia é definido por William Freire et al (2009, p. 339) como -Estudo da Origem das rochas e suas transformações\|
}

No entanto, não resta definido qual a abrangência espacial da compensação, ocasionando divergência na aplicação do dispositivo pela administração pública e dificuldades de execução ao empreendedor.

Isso porque, como lucidamente adverte MILARÉ (2004, p.483):

[...] ao contrário do que ocorre, por exemplo, na legislação urbanística, as normas ambientais são, por vezes, muito genéricas, não estabelecendo, via de regra, padrões específicos e determinados para esta ou aquela atividade. Nestes casos, o vazio da norma legal é geralmente preenchido por exame técnico apropriado, ou seja, pela chamada discricionariedade técnica, deferida à autoridade.

Dessa forma, em que pese o entendimento de que a preservação das cavidades de testemunho deva ser efetivada no mesmo grupo geológico daquela suprimida, conforme o entendimento do artigo $4^{\circ}, \S 2^{\circ}$ do Decreto $\mathrm{n}^{\circ}$ 99.556/1990, não há unanimidade na definição da extensão territorial para execução da medida, compreendida na expressão -área continuall.

$\S 2^{\circ} \mathrm{A}$ preservação das cavidades naturais subterrâneas, de que trata o $\S 1^{\circ}$, deverá, sempre que possível, ser efetivada em área contínua e no mesmo grupo geológico da cavidade que sofreu o impacto. (Incluído pelo Decreto nº 6.640, de 2008).

O vocábulo contínuo, aqui, por conseguinte, se distancia da noção de contíguo, ou seja, de alguma coisa que está ao lado, junta, próxima, vizinha, justaposta, adjacente.

Dessa forma, quando o $\S 2^{\circ}$ do artigo $4^{\circ}$ do Decreto $n^{\circ} 99.556 / 1990$, referenciado ao $\S 1^{\circ}$ do mesmo artigo, determina que o empreendedor adote, como condição para o licenciamento, medidas e ações destinadas a assegurar a preservação, em caráter permanente, de duas cavernas com o mesmo grau de relevância, de mesma litologia e com atributos similares àquela que venha a receber o impacto irreversível, o faz para indicar que, sempre que esta solução seja técnica, geológica e operacionalmente possível ou viável, as cavidades testemunho devem ser mantidas em uma área que apresente continuidade física e densidade quantitativa em termos de ocorrência territorial dessas feições, o que se contrapõe à ideia de fracionamento ou pulverização dessas estruturas por diversas glebas distanciadas entre si.

Esta diretiva regulamentar, bem se ressalte, se alinha ao critério de identificação quanto ao grupo geológico, o que conduz, por princípio, ao enfoque local a que se refere o artigo 14 , 
$\S 1^{\circ}$ da Instrução Normativa $n^{\circ}$ 2/2009, delimitado pela unidade geomorfológica que apresente continuidade espacial, podendo abranger feições como serras, morrotes ou sistemas cársticos (o que for mais restritivo em termos de área), desde que contemple a zona de influência da própria cavidade.

Importante registrar, contudo, que todas essas variáveis indicativas se impõem, nos termos do $\S 2^{\circ}$ do artigo $4^{\circ}$ do multicitado Decreto, apenas por um critério normativo de preferência, não se podendo afastar — se demonstrada a impossibilidade circunstancial—, a hipótese de que se considere, como testemunho, as estruturas cavernícolas desde o enfoque regional, delimitadas a partir de uma determinada unidade espeleológica, que corresponde à área com homogeneidade fisiográfica ${ }^{3}$ geralmente associada à ocorrência de rochas solúveis, que podem congregar diversas formas do relevo carstico e pseudocartisco, tais como dolinas, sumidouros, ressusgencias, vales cegos, lapias, definidas por um conjunto de fatores ambientais específicos.

Sob outra perspectiva, a frase -área do empreendimentoll, veiculada pelo $\S 3^{\circ}$ do artigo $4^{\circ}$ daquele mesmo diploma regulamentar, deve ser compreendida dentro de uma dinâmica polissêmica, abarcando significados mais ou menos abrangentes, dependendo do enfoque dado pelo intérprete.

$\S 3^{\circ}$ Não havendo, na área do empreendimento, outras cavidades representativas que possam ser preservadas sob a forma de cavidades testemunho, o Instituto Chico Mendes poderá definir, de comum acordo com o empreendedor, outras formas de compensação. (Incluído pelo Decreto $n^{\circ} 6.640$, de 2008).

Deveras, não há nada no Decreto $n^{\circ}$ 99.556/1990 que indique unicamente o significado restringente desta expressão, como se área do empreendimento fosse apenas aquela -... efetivamente utilizada ou a ser utilizada para a exploração da atividade objeto de processo de regularização ambientall, o que esvazia, em grande medida, a regência contida no dispositivo, já que não seria lógico - tampouco racional - exigir que o empreendedor acautele cavidades de alta relevância justamente em suas frentes operacionais, onde a própria legislação admite que ele impacte essas feições, como forma de permitir o desenvolvimento de suas atividades.

\footnotetext{
3 -área com homogeneidade fisiográfica [...] que pode congregar diversas formas de relevo cárstico e pseudocárstico [...], delimitada por um conjunto de fatores ambientais específicos para a sua formação\| (§3 art. 14, da Instrução Normativa 02/2009 do MMA, em 21.08.2009)
}

O conceito de -área do empreendimentoll, um tanto nessa linha, deve ser tomado em uma conformação mais ampliativa, como sinonímia de -região do empreendimentoll, acolhendo 
não apenas as porções em que ele se insere fisicamente, como também aquelas em que se repercutem os efeitos de sua implantação e funcionamento.

E tratando-se de critério que emerge no âmbito dos procedimentos de avaliação de impacto e de licenciamento ambiental, mais sensato se mostra aplicar-se à matéria as diretrizes contempladas nos artigos $5^{\circ}$, inciso III e $6^{\circ}$, inciso I, ambos da Resolução CONAMA $n^{\circ}$ 1, de 23.01.1986, que estabelecem os parâmetros delimitadores da área geográfica a ser direta ou indiretamente afetada, bem assim da área de influência do projeto, incorporando, destarte, além da Área diretamente afetada - ADA, a Área de influência Direta -AID e a Área de Influência Indireta - AII.

Artigo $5^{\circ}$ - O estudo de impacto ambiental, além de atender à legislação, em especial os princípios e objetivos expressos na Lei de Política Nacional do Meio Ambiente, obedecerá às seguintes diretrizes gerais:

$[\ldots]$

III - Definir os limites da área geográfica a ser direta ou indiretamente afetada pelos impactos, denominada área de influência do projeto, considerando, em todos os casos, a bacia hidrográfica na qual se localiza;

Artigo $6^{\circ}$ - $\mathrm{O}$ estudo de impacto ambiental desenvolverá, no mínimo, as seguintes atividades técnicas:

I - Diagnóstico ambiental da área de influência do projeto completa descrição e análise dos recursos ambientais e suas interações, tal como existem, de modo a caracterizar a situação ambiental da área, antes da implantação do projeto, considerando:

Ou seja, para fins de adoção de medidas e ações tutelares de duas outras cavidades de alta relevância, para cada uma que for impactada ou comprometida, o espectro territorial é mais dilargado do que a ADA do empreendimento e envolve aspectos físicos, bióticos e até socioeconômicos para além dos limites sob disponibilidade imediata do empreendedor, devendo, em vista disso, ser esgotadas as opções locacionais das cavidades testemunho, antes que se lance mão das opções compensatórias trazidas pela Instrução Normativa $n^{\circ}$ 30/2012.

\section{CONCLUSÃO}

À vista de todo o exposto, conclui-se que, é possível o desenvolvimento de atividades que resultem em impactos negativos irreversíveis sobre cavidades naturais subterrâneas, desde que sejam elas enquadradas como de alta, média ou baixa relevância, conforme os critérios estabelecidos no Ministério do Meio Ambiente, por meio da Instrução Normativa MMA no 2/2009. 
Nesse contexto, apenas as grutas qualificadas como de relevância máxima não podem sofrer quaisquer efeitos adversos, devendo ser compatibilizadas com o Plano de Lavra apresentado pelo minerador, no bojo do processo de habilitação aos direitos minerários correspondentes.

Sob outra perspectiva, sem nos olvidamos dos limites intrínsecos ao conceito de cavidade natural subterrânea, é de se considerar que não havendo, na área do empreendimento impactante, outras feições que possam ser protegidas como testemunho daquelas passiveis de supressão, o artigo $4^{\circ}, \S 3^{\circ}$ do Decreto $n^{\circ}$ 99.556/1990 permite que o Instituto Chico Mendes defina outras formas de adequação compensatória, atualmente regidas pela Instrução Normativa ICMBio no 30/2012.

\section{REFERÊNCIAS}

BECHARA, Erika. Licenciamento e compensação ambiental na Lei do Sistema Nacional das Unidades de Conservação (SNUC). São Paulo: Atlas, 2009.

BRUNDTLAND, Gro Harlem. Our Common Future: From One Earth to One World. Nova York: Oxford University Press, 1987.

FREIRE, William. Dicionário de Direito Ambiental e Vocabulário Técnico do Meio Ambiente / William Freire, Daniela Lara Martins (Coord.) 2.ed. Jurídica Editora, 2009.

MILARÉ, Edis. Direito do ambiente. São Paulo: Revista dos Tribunais, 2004.

MILARÉ, Edis. Direito do ambiente. São Paulo: Revista dos Tribunais, 2014.

MIRANDA, Marcos Paulo de Souza. Mineração em áreas de ocorrência de patrimônio espeleológico. Revista MPMG Jurídico, Belo Horizonte, edição especial, p. 53-60, 2012.

HENKES, Silviana L. GASTAL, Alexandre Fernandes. Mielke, Priscila. O direito-dever à cultura e à preservação do patrimônio cultural. Revista Veredas do Direito, Belo Horizonte, v.10, n.20 p.231-255 Julho/Dezembro de 2013.

SILVA, José Afonso da. Comentário contextual à Constituição. São Paulo: Malheiros, 2005 . 